\title{
The Effect of Deduction and Induction Methods Used in Modelling Current Environmental Issues with System Dynamics Approach in Science Education
}

\author{
Hasret Nuhoğlu* \\ Maltepe University, Special Education Department, Istanbul, Turkey \\ ORCID: 0000-0002-9985-4203
}

Article history

Received:

14.11.2019

Received in revised form: 25.01.2020

Accepted:

03.02.2020

Key words:

System dynamics in education, environmental education, induction-deduction modelling, science education
The main goal of this research is to study the effect of modelling with system dynamics on learning. Specifically, this research studies if using inductive or deductive learning methods applied during modelling with system dynamics has any effect on problem solving skills of students. This research has three other goals: Firstly, the successful application of system dynamics approach in teaching environmental topics. Secondly, helping students to be aware of the environmental problems. Thirdly, helping students to build solution-oriented system dynamics models. An experimental design without control group with pretest/posttest is used in the research. The sample of the research consists of 40 students at 7 th grade. Experiment continued an hour per week for the entire semester of 14 weeks. The students in the experiment group 1 developed their models using inductive method. The students in the experiment group 2 developed their models using deductive method. Problem solving skill inventory developed by Heppner and Petersen (1982) was used for data collection. The data collected was analyzed statistically. As part of the statistical analysis, the researcher evaluated the model records developed by students, interviews done with students and observational records of teachers. Statistically significant differences were observed in the problem-solving skills of students in both groups after the experimental study. The increase in the mean scores for problem solving skills of the experimental group 1 was higher than the increase in the mean scores of the students in the experimental group 2. System dynamics approach, which is effective in decision making process, also plays an important role in improving students' problem-solving skills.

\section{Introduction}

The world that is in continuous change requires individuals that are devoted to learning lifelong. The novel education paradigm aims to develop individuals that learn how to learn and identify cause and effect relationships on their own. In fact, one of the most critical issues of education is that children that are naturally curious minded and own the enthusiasm to make discoveries yet they lose these abilities as they grow up. Our current education system lacks in nurturing imagination skills and willingness of learning for children. The Turkish educational system has to be supported with educational approaches that reinforce the development of

\footnotetext{
*Correspondence: hasretnuhoglu@ maltepe.edu.tr
} 
innate skills of children, orient them to creative thinking and self-learning. Ministry of National Education (MNE) (2006) in Turkey aims to solve this problem using learning methods based on constructive learning in their new instruction programs. Constructive learning is an education philosophy that can solve these problems. System dynamics approach is an interdisciplinary learning approach based on constructive learning philosophy.

System dynamics approach has been used in various fields for a long time. The Rome Club study done in 1970's (Meadows, Meadows, Randers \& Behrens, 1972; Forrester, 1973) is the most popular system dynamics study. This study showed that, if no precautions are taken, balance of nature on Earth will be severely destroyed by the year 2000. There have been many debates going on after this study, but upon the discovery of the ozone layer hole in 1980s, the world public and the political leaders were forced to consider taking immediate precautions. As a result of these precautions, common decisions were taken and put into action by all the countries of the world regarding gasses that destroy ozone layer and cause greenhouse effect and also related to some other environmental problems.

System dynamics research, similar to the Rome study, resulted in important changes in certain fields such as business systems (Sterman, 2000), ecological systems (Grant, Pedersen, \& Marín 1997), socio-economic systems (Forrester, 1969, $1971 \&$ Meadows, 1973), agricultural systems (Saysel, Barlas, \& Yenigun, 2002), political decision systems (Nail, Gelanger, Klinger, \& Peterson 1992) and environmental systems (Vizayakumar \& Mohapatra, 1991; Vezjak, Savsek, \& Stuhler, 1998; Ford, 1999; Wood \& Shelley; 1999, Abbott \& Stanley, 1999; Deaton \& Winebrake, 2000; Guo, Liu, Huang, Fuller, \& Yin, 2001). Inspired by this body of research, system dynamics researchers aimed to improve the quality of education by adapting this approach to the field of education. Initial educational studies based on system dynamics (Forrester, 1996) indicate that it is possible to obtain substantial results in this area, too. In the schools where system dynamics approach was implemented, it was observed that students were taking on voluntary projects related to course material even after-schools hours, and they got involved in curriculum so much and even, from time to time, they included their parents in the course projects.

As a result of the increase in students' interest in and understanding of course material, system dynamics researchers were expecting that this approach would be incorporated to the educational system in the US. But since then, it has been observed that the applications of this approach have not reached a satisfactory level (Forrester, 1996). There are various views about the reasons of this shortcoming. Some of the most probable reasons are as follows: There has been no focus on developing lesson plans and activities supported by pedagogical methods while implementing system dynamics approach at K-12 level. Teachers were concentrating on the rules of system dynamics, and ignoring the practical principles related to implementation (Forrester, 1996; Lyneis, 2000). To rectify this, curriculum projects based on system dynamics, Stacin (Mandinach \& Cline, 1994), Cc-Stadus (Zaraza, 1995), Cc-Sustain and Science Ware (Alessi, 2005), have been developed. These projects supplied teachers with new ideas and many useful models.

System dynamics approach enable students to focus on the causes of phenomena and understand that complex systems have many underlying cause and effect relationships and these relationships cannot be resolved superficially. In addition, as a general problem defining and solving approach, it helps students have the discipline and sensitivity of a scientist, develop skills such as discovering new problems by observing the environment, as well as modeling and analyzing these problems using a scientific approach. 
System dynamics is a method used for understanding how complex systems change over time. With the help of system dynamics approach, simulation environments called "micro world" are constructed. Within this environment, students can carry out experiments repeatedly using this model instead of the real world. This allows students to learn, through experience, how system dynamics approach works. They find the opportunity to observe experiments in this micro world that would not be possible to experience the same otherwise. At the elementary school level, experiments in simulation environments are usually done using the program called STELLA (System Thinking Educational Learning Laboratory with Animation).

While using system dynamics tools, teachers have realized that the learning that takes place is cooperative and student centered. In traditional educational settings, the teacher sits in front of the class, delivers information to the students who are passive receivers, whereas in the system dynamics approach, the teacher promotes research and helps students develop the responsibility of learning on their own. System dynamics fosters investigation of case studies, problem posing and collaboration to solve problems (Forrester, 1996; Lyneis, 2000). System dynamics lessons are enjoyable for both teachers and students. The curriculum was recently revised in Turkey. This new curriculum is relatively more learner centered and it aims to train individuals who are capable of reasoning, collaborating and providing alternative solutions to problems that they may come across in future. The systems dynamics applications in the literature indicate that system dynamics approach is an effective tool for training such individuals.

In light of this information, the current study aims to investigate whether using inductive and deductive reasoning while modeling with system dynamics approach has any effect on students' problem solving skills. Other aims include adopting system dynamics approach to teach current environmental topics, helping students to become aware of the current environmental problems, and supporting them to develop models that will provide solutions to these problems.

Background (underlying) goals of the study are as follows:

1. To find concrete evidence related to increasing the quality of education through system dynamics approach.

2. To develop teaching materials that will help teachers see how the system dynamics approach can be incorporated to various environmental topics.

3. To help students develop thinking skills such as understanding of cause and effect relationships, creative thinking, problem solving and decision making.

4. To create a learner centered, multi-disciplinary learning environment.

The ultimate goal in the long term, is to make system dynamics approach a regular feature of Turkish national educational policy and to support lifelong learning, in order to help students become individuals who can explore, question, identify problems around them and provide alternative solutions to these problems.

\section{Methodology}

An experimental design without control group and pre-test and post-test was used in the research. The independent variable whose influence is investigated on the experimental group 1 is "Deductive Method Based on System Dynamics", on the experimental group 2 is "Inductive Method Based on System Dynamics". The scores of pre-tests and post-tests are compared between groups and inside groups. The sample of the research is 40 students ( 20 in experimental group 1, 20 in experimental group 2) at 7th grade. The students in the experimental group 1 developed the system dynamics-based model using inductive method, the ones in the 
experimental group 2 developed it using deductive method. Table 1 presents how the study is performed in the experimental 1 and experimental 2 groups in detail.

\section{Data Collection Techniques and Tools}

The following measurement and evaluation tools were used in the research:

a) "Problem Solving Skill Inventory" developed by Heppner and Petersen (1982) that measures the problem-solving skills of the individual

b) Model records made by the students

c) Observational records written by the teachers and the researcher. Semi-structured interviews made with the students during the study.

\section{Problem Solving Skills Inventory}

This inventory developed by Heppner and Petersen (1982) evaluates how individuals perceive their problem solving skills. It is a 6 point Likert-type scale consisting of 35 items. As a result of factor analysis, 3 constructs emerged: Problem-Solving Confidence, ApproachAvoidance Style, and Personal Control. Items numbered 9, 22 and 29 were discarded. Cronbach alpha reliability coefficient was $\alpha=0,90$. Turkish adaptation of the inventory was carried out by Şahin, Şahin and Heppner (1993).

In addition, Nuhoğlu (2009) conducted reliability and validity analysis of the inventory (Turkish version) for middle school students. First tryout of the instrument, which contained 30 items measuring attitudes towards problem solving skills, was conducted to 215 students from grades 6 to 8. Data collected from this pilot study was analyzed to check reliability. According to factor analysis results, 10 of these 30 items (items 4, 7, 9, 10, 11, 15, 23, 25, 27 and 30) were removed from the instrument. 13 of the remaining items were positive, 7 of them were negative. Cronbach Alpha reliability coefficient was found as $\alpha=0,826$. In the fields of social and educational science, such a coefficient value is considered as an indicator of high reliability.

In order to check the validity of the Problem-solving skills inventory, both content and construct validity analyses were carried out. Construct validity was established by collecting expert opinions, factor analysis was conducted to ensure construct validity and, Kaiser-Meyer-Olkin (KMO) test was used to check sampling adequacy. Kaiser-Mayer-Olkin (KMO) was found to be 0,818 and Barlett value was 871,179 ; which indicate that factor analysis can be performed, and items correlate with each other.

\section{Model Records}

The observations, model records and data collected from the interviews were expressed according to five criteria (Nuhoğlu, 2009). These criteria are the following:

- Criterion1 - Using the correct concepts in the model: This criterion measures to what degree students correctly use basic concepts related to the topic of the model they have developed. To check whether this criterion is satisfied, qualitative data collected via observations were examined. During their model development phase, students were asked verbally what the scenario was about and what they were supposed to do in relation with the scenario. Their answers were recorded by the researcher. This criterion was also evaluated by examining the final versions of students' models. 
- Criterion 2 - Determining and using the variables: This criterion is used to decide how students determine stock, flow and converter variables. Data related to this criterion is obtained from recordings of students' models.

- Criterion 3 - Determining the relationship between the variables: Students' ability to determine the relationship between the basic variables of the model is examined using this criterion.

- Criterion 4 - Locating numerical parameters: This criterion is used to check whether the students can correctly locate the research parameters on their model.

- Criterion 5 - Creating and interpreting graphs: Determine whether the students can create the graph of their models correctly and are able to interpret the resulting graph.

\section{Student Beliefs and Observation Logs}

The observation notes recorded by the researcher and observer teachers during the modeling phase were also examined. In addition, unstructured interviews were conducted with students and their answers to open ended questions were recorded by a voice recording machine. These were then transcribed and evaluated. Transcription was done with the help of two observer teachers. Student responses were evaluated and reported separately by three people.

\section{Data Analysis}

Quantitative data were analyzed to see whether there were any significant differences in students' problem-solving skills. Dependent samples t-test was conducted to compare mean scores of pre and post tests of the groups. The independent t-test was performed for the same content according to two separate methods in two groups selected as an empirical study and to evaluate the effectiveness of the methods at the end of the study.

Content analysis was carried out on qualitative data. An ID number was assigned to each participant and these ID numbers were used during analysis. Two researchers coded the data independently. Both researchers examined data collected from the workbooks, interviews and the program evaluation form independently and took notes. The second round of evaluations was done to reveal repetitions, similarities, and differences. In the end, categories emerged reflecting student views. Researchers independently formed quantitative charts based on these categories. Then these charts were compared by counting the number of agreements and disagreements. Reliability was established with the Miles and Huberman formula: Reliability $=$ (number of agreements) / (number of agreements + number of disagreements). Formula revealed that researchers were in agreement $85 \%$ during the process.

Participants' quotes given in the results section are identified using symbols $n(B / G)_{x}$ where " $n$ " represents participants' group experimental 1 or experimental 2 (E1 or E2), "B" or "G" their gender and " $\mathrm{x}$ " their ID number. For example, "E1G 12 " means "experimental group girl with ID number 12".

\section{Implementation Stages}

Experimental study lasted a semester, one hour each week, 14 hours in total. During the first 6 weeks in the experimental group 2, basic concepts related with systems thinking and system dynamics approach were explained through different games and activities in accordance with constructive learning principles, then STELLA program was introduced. In the next eight weeks, students worked as a group of two, as they chose one of the proposed environmental 
problems developed models. In the experimental group, students were first introduced with System Zoo 2 simulation book inside Simulation Models Climate, Ecosystems, Resources developed by Bossel, (2007) Then basic concepts related with system thinking and system dynamic approaches were presented using that model. At the same time, students were asked to develop a model for one of the environmental problems.

Topics in Experimental group 1 / Experimental group 2

Theory of systems

Dynamic and static systems and related examples

Systems thinking

Historical development of system dynamics

Basic elements of the system

- $\quad$ Stock-flow diagrams

- Causal relationships

- $\quad$ Feedback loops

Table 1. How Topics are Thought in the Experimental Group 1 and Experimental Group 2

\begin{tabular}{|c|c|c|}
\hline & Experimental group 1 INDUCTION & Experimental group 2 DEDUCTION \\
\hline \multirow{3}{*}{$\begin{array}{l}\text { Introduction to } \\
\text { System Dynamics } \\
\text { (Weeks 1-6) }\end{array}$} & Introducing the topics one by one & \multirow[t]{2}{*}{ Introduction of the system and } \\
\hline & Introducing STELLA program & \\
\hline & Working on sample scenarios & $\begin{array}{l}\text { Elements of the system on a sample } \\
\text { model }\end{array}$ \\
\hline \multirow{2}{*}{$\begin{array}{l}\text { Preparation for } \\
\text { Modelling } \\
\text { (Weeks 7-8) }\end{array}$} & Determining the study groups & \multirow{4}{*}{$\begin{array}{l}\text { Modelling } \\
\text { Determining the study groups }\end{array}$} \\
\hline & Choosing the topic for modelling & \\
\hline \multirow{6}{*}{$\begin{array}{l}\text { Modelling } \\
\text { (Weeks 9-13 ) }\end{array}$} & Stage 1: I am curious about the system & \\
\hline & Stage 2: I am discovering the system & \\
\hline & $\begin{array}{l}\text { Stage 3: I am getting familiar with the } \\
\text { system }\end{array}$ & Choosing the topic for modelling \\
\hline & Stage 4: I am modelling the system & Developing a model \\
\hline & Stage 5: I am evaluating the system & environmental problems \\
\hline & $\begin{array}{l}\text { Creating the model by connecting each } \\
\text { element of the system }\end{array}$ & Interpreting the model \\
\hline $\begin{array}{l}\text { Presentation of the } \\
\text { Models } \\
\text { (Week 14) }\end{array}$ & Student presentations & \\
\hline
\end{tabular}

\section{Environmental Topics Offered to the Students}

Student groups were asked to choose one of the 14 available topics (given in Table 2) and conduct a research on this topic. They were then asked to develop a model using STELLA program. Students in the experimental group 1 group worked inductively during modeling while the experimental group 2 worked deductively.

Table 2. Offered Study Topics

\begin{tabular}{ll}
\hline 1 & Energy flow in the food chain \\
2 & Water cycle \\
3 & Carbon cycle \\
4 & How epidemic diseases are spreading \\
5 & Traffic problem \\
6 & Young and adult bluefish problem in Turkey \\
7 & Caffeine addiction \\
8 & Alcohol addiction \\
9 & Drug addiction
\end{tabular}


10 Relationship between population and natural sources

11 Medicine absorption

12 Predator-prey relationship

13 Management of a country or a company

14 Comparison of populations of five different countries (Tanzania, Turkey, United States, India, Russia)

\subsection{A Sample Model That Students are Expected to Develop}

In this section, an ideal model that students are expected to develop is given as an example. This is a model explains the predator-prey relationship. Table 3 shows the model, the related mathematical data and how the model works.

Table 3. A sample model about predetor prey relationship

Topic Predator Prey Relationship

Model

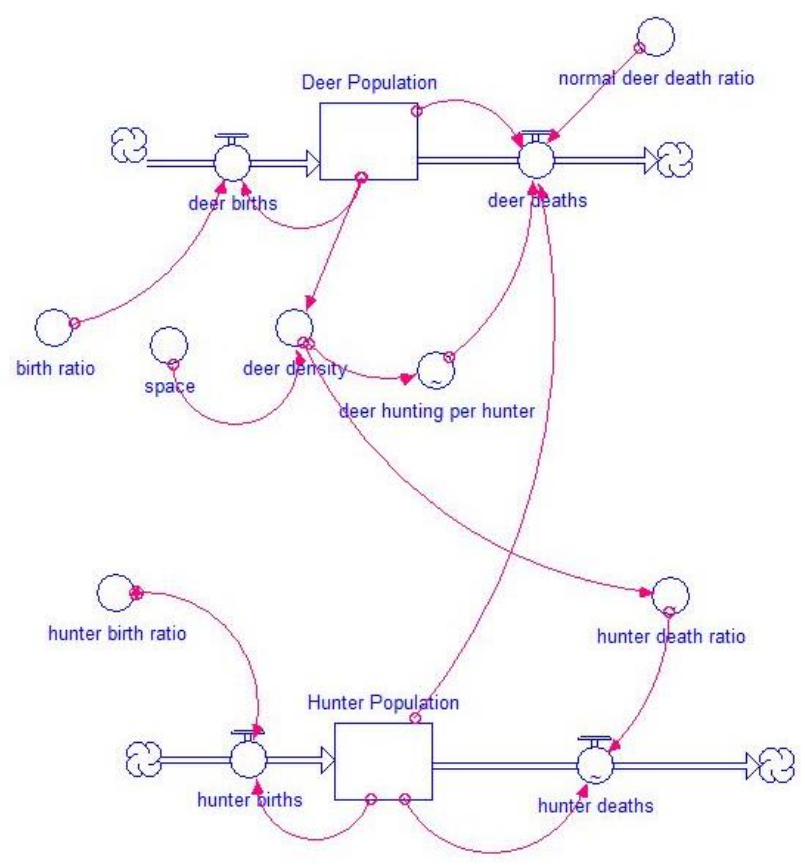

\footnotetext{
Mathematical $\square$ Deer_Population $(\mathrm{t})=$ Deer_Population( $(\mathrm{t}-\mathrm{dt})+$ (deer_births - deer_deaths) * dt

Data

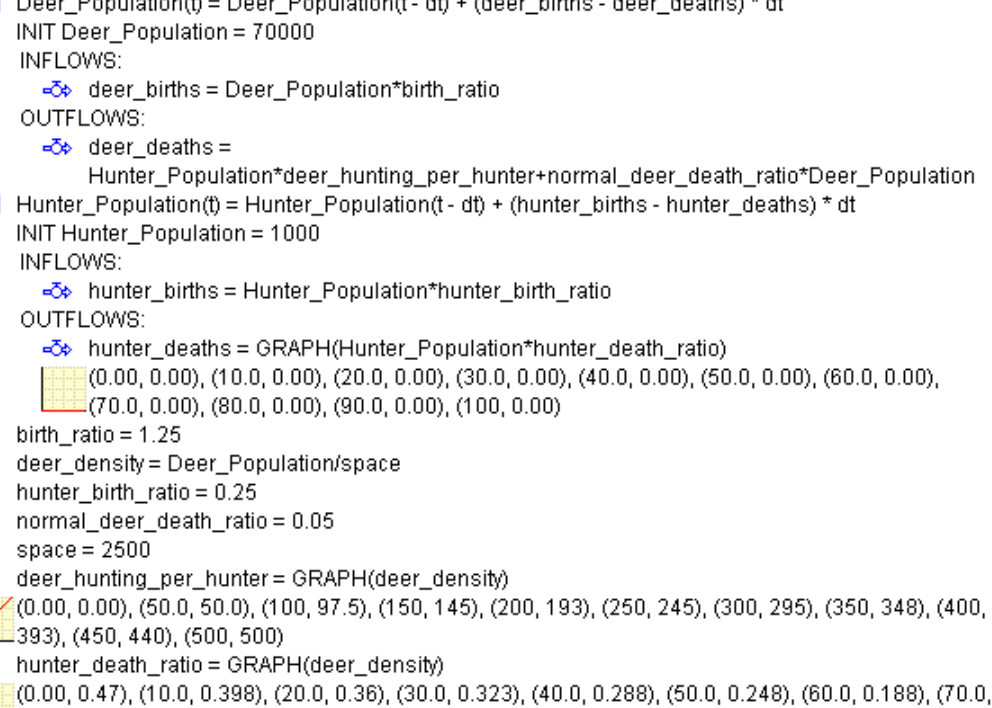




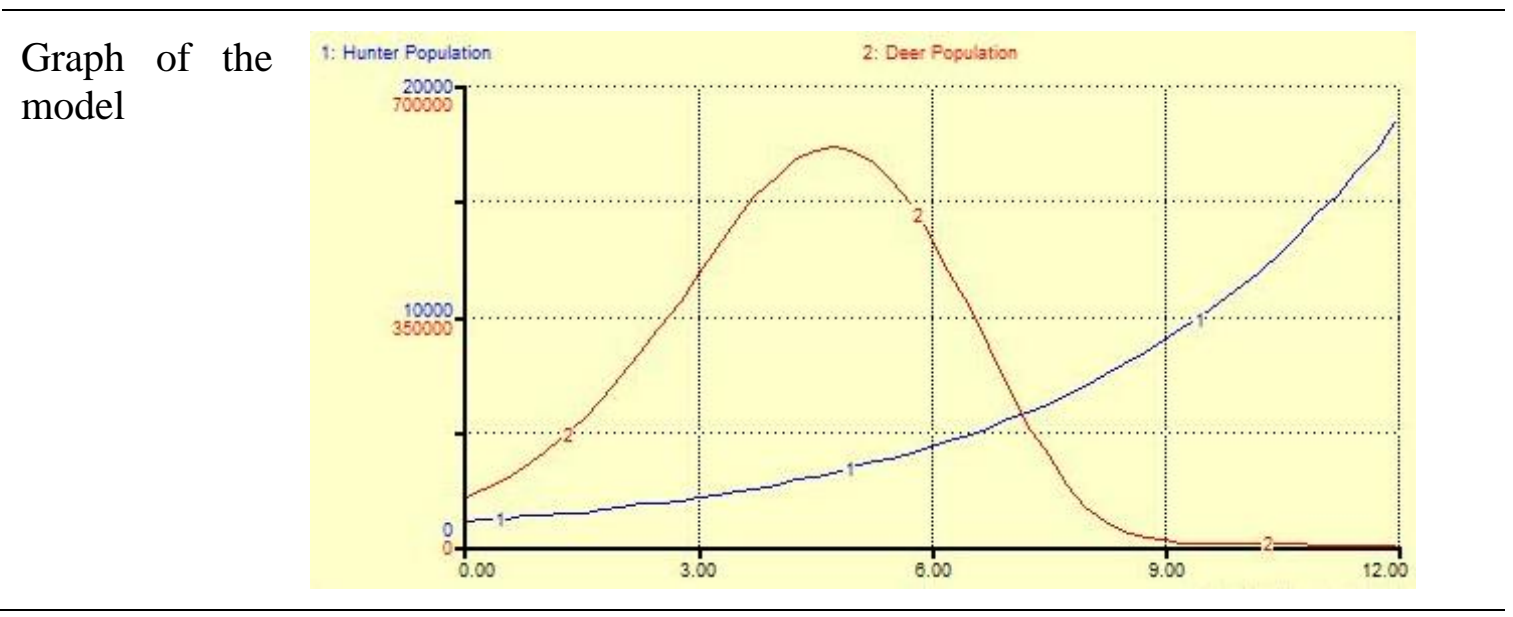

\section{Findings}

\section{Findings Related to Problem Solving Skills of the Students in the Experimental Group 1 and Experimental Group 2}

In order to determine whether there was a significant difference between problem solving skills scores of experimental group 1 and experimental group 2 prior to the experiment, independent samples t-test was conducted. The results can be seen in Table 4 below:

Table 4. Independent Samples T-Test Results for the Problem-Solving Skills Pretest Scores

\begin{tabular}{llllll}
\hline Group & $\mathbf{N}$ & $\bar{X}$ & $\mathbf{S}$ & $\mathbf{t}$ & P \\
\cline { 1 - 4 } Experimental 1 (E1Pre) & 20 & 73,45 & 11,83 & 1,49 & 0,07 \\
\cline { 1 - 4 } Experimental 2 (E2 Pre) & 20 & 68,00 & 12,69 & & \\
\hline
\end{tabular}

When Table 4 is examined, it is seen that mean pretest scores of students in both groups are close $\left(\bar{X}_{\text {experimental } 1}=73,45 ; \bar{X}_{\text {experimental } 2}=68,00\right)$. There is no significant difference between problem solving skills scores of the students before the experiment $(t=1.49 ; p>0,05)$. Pretest and posttest problem solving skills scores of the students in the experimental group 1 are given in Table 5.

Table 5. Pretest and Posttest Problem Solving Skills Scores of the Students in the Experimental Group 1

\begin{tabular}{llllll}
\hline Group & $\mathbf{N}$ & $\bar{X}$ & $\mathbf{S}$ & $\mathbf{t}$ & $\mathbf{P}$ \\
Experimental 1 (E1 Pre) & 20 & 73,45 & 11,83 & 13,79 & 0,00 \\
Experimental 1 (E1 Post) & & 123,80 & 7,4 & & \\
\hline
\end{tabular}

It is seen that mean scores for problem solving skills of the experimental group 1 students increased after the experiment and the difference between pretest and postest scores were statistically significant $(\mathrm{t}=-13,79 ; \mathrm{p}<0,05)$. Table 6 shows the $\mathrm{t}$-test results related to pretest and posttest problem solving skills scores of the experimental group 2.

Table 6. t-test results related to pretest and posttest scores for problem solving skills of the experimental group 2.

\begin{tabular}{|c|c|c|c|c|c|}
\hline Group & $\mathbf{N}$ & $\bar{X}$ & $\mathbf{S}$ & $\mathbf{t}$ & $\mathbf{P}$ \\
\hline Experimental 2 (E2 Pre) & \multirow[t]{2}{*}{20} & 68,00 & 12,69 & \multirow[b]{2}{*}{$-8,22$} & \multirow[b]{2}{*}{0,00} \\
\hline Experimental 2 (E2 Post) & & 92,75 & 10,00 & & \\
\hline
\end{tabular}


There is a significant difference between the pretest and posttest scores for problem solving skills of the experimental group $2(\mathrm{t}=-8,22 ; \mathrm{p}<0,05)$. Mean problems solving scores for the post test is significantly higher than the pretest scores. The comparison of posttest scores of experimental group 1 and experimental group 2 after the experiment are given in Table 7.

Table 7: Independent Samples t-Test Results for Posttest Scores of the Experimental Group 1 and Experimental Group 2

\begin{tabular}{llllll}
\hline Group & $\mathbf{N}$ & $\bar{X}$ & $\mathbf{S}$ & $\mathbf{t}$ & $\mathbf{P}$ \\
\cline { 1 - 4 } Experimental 1(E1 Post) & 20 & 123,80 & 7,4 & 11,23 & 0,00 \\
\cline { 1 - 4 } Experimental 2 (E2 Post) & 20 & 92,75 & 10,0 & & \\
\hline
\end{tabular}

The results indicate a significant difference between pretest scores $(t=11,23 \mathrm{p}<0,05)$. System dynamics approach has a positive impact by improving students' problem solving skills $(\bar{X}$ experimental $\left.1=123,80 ; \bar{X}_{\text {experimental } 2}=92,75\right)$.

\section{Findings Related to System Dynamics Model Records of the Students in the Experimental Group 1 and Experimental Group 2}

Findings related to system dynamics model records of the students in the experimental group 1 and experimental group 2 are examined with respect to five criteria as shown in Table 8 .

Table 8: Findings related to students' model records

\begin{tabular}{|c|c|c|c|c|c|c|}
\hline \multirow[t]{2}{*}{ Criteria } & \multirow{2}{*}{\multicolumn{2}{|c|}{ Content of Criteria }} & \multicolumn{2}{|c|}{ Experimental Group 1} & \multicolumn{2}{|c|}{$\begin{array}{l}\text { Experimental } \\
\text { Group 2 } \\
\end{array}$} \\
\hline & & & f & $\%$ & f & $\%$ \\
\hline Criterion 1 & \multicolumn{2}{|c|}{ Using the correct concepts } & 19 & 95 & 19 & 95 \\
\hline \multirow[t]{4}{*}{ Criterion 2} & Stock & Determining the stock & 19 & 95 & 19 & 95 \\
\hline & \multirow[t]{2}{*}{ Flow } & Determining the stock & 18 & 90 & 17 & 85 \\
\hline & & Direction of the flows & 18 & 90 & 16 & 80 \\
\hline & Converter & Determining the converters & 16 & 80 & 14 & 70 \\
\hline \multirow[t]{3}{*}{ Criterion 3} & \multirow{3}{*}{$\begin{array}{l}\text { Determining } \\
\text { relationships }\end{array}$} & Stock-flow relationship & 15 & 75 & 12 & 60 \\
\hline & & $\begin{array}{l}\text { Intermediate variable-stock } \\
\text { relationship }\end{array}$ & 13 & 65 & 10 & 50 \\
\hline & & $\begin{array}{l}\text { Intermediate variable-flow } \\
\text { relationship }\end{array}$ & 13 & 65 & 8 & 40 \\
\hline Criterion 4 & Mathematical data & $\begin{array}{ll}\text { Locating } & \text { numerical } \\
\text { variables } & \end{array}$ & 10 & 50 & 8 & 40 \\
\hline \multirow[t]{2}{*}{ Criterion 5} & \multirow[t]{2}{*}{ Graphing } & Creating the graph & 9 & 45 & 7 & 35 \\
\hline & & Interpreting the graph & 9 & 45 & 5 & 30 \\
\hline
\end{tabular}

When Table 8 is examined, it is seen that students in the experimental group 1 and experimental group 2 were successful at easily determining the basic elements of the system, stock and flow. However, they had difficulties in determining the other variables that affect the system. Specifically, students in the experimental group 2 had more difficulties in determining relationships than students in the experimental group 1. It was observed that while determining the relationship between converter and flow, they drew the direction of the relationships incorrectly. These mistakes impacted the final graph of their model. On the other hand, students in the experimental group 1 made fewer mistakes while they were developing their models, because they were deductively constructing their model as opposed to the experimental group 2 who were building their model step by step in an inductive fashion. 


\section{Opinions of the Students in the Experimental Group 1 and 2 Related to System Dynamics Modelling}

In this section, student views gathered by the unstructured interviews conducted with the participants are presented.

Data collected by the interviews were examined under the following categories: The changes in students' interest in understanding current issues, difficulties they encountered during the system dynamics modeling process, what students gained from system dynamics approach.

\section{Changes in the interest towards learning:}

Students in the experimental group 1 and 2 stated that, after the experimental study, they became more interested in current issues and paid attention whenever they heard some news about these issues. They also mentioned that while developing models about environmental problems, instead of breaking the problem into pieces, it had to be considered as a whole. Students also pointed out that they realized they started to look for relationships among all kinds of subjects.

Some student opinions are as follows:

$\mathrm{E}^{2} \mathrm{~B}_{02}$ "I was very surprised that epidemic diseases are spreading so fast. There are many factors that we have not thought of before."

$\mathrm{E}_{1 \mathrm{G}} \mathrm{H}_{12}$ "Previously I was trying to find solutions to the traffic problem by myself and offering simple solutions. I never thought traffic problem could be this complicated."

$\mathrm{E}^{2} \mathrm{G}_{07}$ "While I was modeling, I learned that natural sources are related to population growth and this relationship is really important."

E2B 13 "While I was building a model for medicine absorption with my friend, we found the opportunity to examine the contents of the medicines that we take. I don't ask my mom to give me medicine whenever a part of my body is aching anymore."

$\mathrm{E}_{1 \mathrm{G}}{ }_{12}$ "I had been watching young-adult bluefish problem in the news but I had not fully understood what it was about. Before starting modeling with STELLA, we did some research with my friend and with the model we developed, we now have a better understanding of the reasons why young bluefish should not be caught. Whenever I hear a news about this problem now, I explain my parents the details of the situation."

E1B 16 "With the STELLA approach, I began to see phenomena as a whole. I learned that every event is related to each other and everything affects each of us. This was very surprising for me."

\section{Difficulties encountered during the modeling phase}

Students stated that, after doing some research on the topic, they did not have any problems in determining the stocks yet they had some difficulty deciding the directions of the flows at first-later figuring it out after a couple of tries. According to the students, the hardest part was to understand how pieces influenced each other while they were determining relationships between variables. Besides they stated that, after the model was formed, they made mistakes writing the mathematical equalities, encountered difficulties when they had to write formulas instead of quantitative expressions. Also, when the graphs were wrong they 
realized they had to go back and correct the model and had to do this a couple of times, then they got frustrated but somehow did not give up without fixing it. It was noticed that, since the students in the experimental group were working from whole to parts as they built the model first and then tried to add the parts affecting the system in it, they made less mistakes compared to the students in the experimental group 2.

Some student opinions are as follows:

$\mathrm{E}_{1 \mathrm{G}} \mathrm{G}_{11}$ While modeling the water cycle, it seemed like the direction of the flows was apparent but we were arguing with my friend when we were determining the directions; I argued that there should be an inward flow and my friend thought it should be outward. We discussed it and reached an agreement. We also had difficulty in deciding what the converters affecting the water cycle should be in the model.

E2 $\mathrm{BG}_{05}$ The biggest difficulty I experienced was in deciding who was related to whom and which one was affecting the other, because one variable seemed to be affecting a second variable but at the same time it could also be affecting another variable. This was confusing me a lot."

$\mathrm{E}_{1 \mathrm{G}} \mathrm{g}_{9}$ We thought with my friend that we couldn't correctly write numbers in the model, because we kept getting a constant graph. We were writing the numbers, but we also wrote numbers where we were supposed to write formulas so our graph turned out to be wrong. The difficult part for us was to place the numbers on the model.

E2 $\mathrm{G}_{04}$ To be honest, I was a little bit bored with constant adjustments made in the model; I wanted to get the graphic part right away. But we kept making mistakes and turning back to the model. I wanted to finish the model as soon as possible.

\section{What students gained from system dynamics approach (learning outcomes)}

With systems dynamics approach, students learned to see phenomena as a whole. They realized that when faced with a problem, they need to spend some time to figure out how to solve it, and problems may have more than one solution. Students saw that the outcome of an event could be something unexpected and when phenomena affect each other differently, the outcome changes.

Here are some of the student quotes:

$\mathrm{E}_{2} \mathrm{~B}_{12}$ "We never thought things would be this complicated when we chose to model the traffic problem. We kept adding more and more variables...then it became too complicated for us. After that we removed some of the variables and our model became simpler."

$\mathrm{E}_{1 \mathrm{G}} \mathrm{1}_{18}$ "I saw how one event affects the other. After we finished the model, it was very surprising to see that the solution I had in mind at first did not work."

$\mathrm{E} \mathrm{B}_{03}$ "During modeling we kept coming across problems, we worked hard to overcome a problem, just after we finally solved it, we came across another. I think at the end of the process, we developed resistance to problems."

E2 $\mathrm{G}_{06}$ When we first started developing our model, we kept adding each variable we learned about to our model, and then we realized that our model became huge and difficult to understand. We thought about what we could do, we examined our 
friends' models and we decided to keep it simple. We built the model in its simplest form, drew the graphs, and then we improved our model.

\section{Discussions}

Most of the educational studies are about teaching system dynamics approach to students from different age groups, through different topics. There are some studies (Evans, 1988; Shaffer, 2006) on subjects such as computer programming, management and psychology at the university level, but a majority of the studies (Davidsen, Bjurklo, \& Wikström, 1993; Draper \& Swanson, 1990; Schecker, 2005; Cruz, González, Restrepo \& Zuluaga, 2007; Zuman \& Weaver, 1988; Tinker, Nemirovsky, Mokros, \& Barclay, 1990; Fisher, 2011) investigate the effects of system dynamics approach on high school students' achievement and improvement of their various skills. System dynamics approach was used in high school physical and social science subjects such as economics, social ecology, population, mechanics, and Newton's laws of motion as well as mathematics. In studies related to applications of system dynamics approach at the primary school level (Draper \& Swanson, 1990; Penner, 2000; Hassell, 1987; Webb, 1988), the topics worked on were simpler compared to high school and software programs other than STELLA were tested. Results of these studies indicate that, system dynamics approach can be adapted to preschool successfully (Ticotsky, Quaden, \& Lyneis, 1999) as well. Apart from the studies focusing on adaptation of system dynamics approach to school, there are also studies on developing curriculum plans and course descriptions based on system dynamics approach (Schecker, 1994; Albin, 1996; Zaraza \& Fisher, 1997; Fisher, 2000; Lyneis \& Fox-Melanson, 2001). Furthermore Andersen, LaVigne, \& Stuntz (2013), created online curriculum material for K-12 students with Characteristics of Complex Systems Project (CCSP).

When literature is examined, it is witnessed that there are not many studies at the primary school level and teaching materials that can be used in implementation are limited. Furthermore, there is not enough information about the problems faced during implementation. In this study, system dynamics approach is implemented at the middle school level; with a view to helping students begin constructing knowledge at an earlier age and fostering their desire and need to learn new things using technology. With system dynamics approach, students developed models for dynamic systems related to various environmental problems, and difficulties encountered during modeling phase were recorded. This study aims to contribute the literature with new ideas and applications.

While systems dynamics approach is used in various fields in the U.S.A and many European countries, in Turkey it is mostly used in engineering. Fisher (2011), stated that system dynamics modeling concepts that have been successfully taught for 20 years to students in the U.S.A., ages 5-18 years, are presented, with high-lights describing some of the lessons/activities used. First system dynamics applications in the educational field were done by Nuhoğlu (2008) in Turkey. The current research is conducted with the aim of increasing the use of system dynamics approach at the primary school level.

Education teaches a static image of the real world. But problems in the real world are dynamic (Forrester, 1992). Therefore, system dynamics modeling is being used in educational period from preschool to undergraduate level, in the fields of mathematics, physics, social studies, history, economics, biology and literature (Forrester, 1996).

Most of the research in the literature (Davidsen, Bjurklo, \& Wikström, 1993; Draper \& Swanson, 1990; Schecker, 2005; Cruz, González, Restrepo \& Zuluaga, 2007) reports that, while 
the system dynamics approach has a positive impact on students and teachers, some problems occur at the execution/application level. Students usually tend to confuse stock with flow (Forrester, 1992). They also cannot differentiate flow and cause-effect relationship. They are inclined to constructing unnecessarily complex and abstract models instead of ones that reflect reality. They have the tendency to adapt models in textbooks or shown by their teachers when they should develop their own models. The biggest mistake teachers make here is reported as assuming that their students can develop a complex model (including multiple stocks, flows and cause and effect relationships) within a few weeks (Alessi, 2005). Similar difficulties were observed in this study as well. Since these difficulties were detected in the literature beforehand and thereupon the necessary precautions were taken, the students were able to proceed with higher levels of awareness and made fewer mistakes during the modeling phase.

According to the results of Fisher's (2011) workshops in math course, some very interesting, new problem scenarios were introduced to students (drug models, resource models, predator/prey models, etc.), stimulating both teachers and students to maintain an interest in the use of system dynamics models. Andersen, LaVigne, \& Stuntz (2013), enabled students to work with more complex models via the project called "characteristics of complex systems". Students developed models where they acted as Wildlife Manager (managing the prey population of the predator-prey-biomass model), Peer Coach (advising fellow students regarding burnout cycles) and Local Newspaper Journalist (investigating hog farming for the commodity market versus raising heritage breeds of hogs for a more specialized market). In line with these studies related to system dynamics, students in the current study also developed models about environmental issues; such as energy flow in the food chain, how epidemic diseases are spreading, management of a country or a company.

\section{Conclusion and Suggestions}

There were no significant differences between problem solving skills scores of the students in the experimental group 1 and 2 . The experiment has no deviation. The participant students had equal problem-solving skills at the beginning of the study. Statistically significant differences were noted in the problem-solving skills of students in both groups after the experimental study. The increase in the mean scores for problem solving skills of the experimental group 1 was higher than the increase in the mean scores of the students in the experimental group 2. System dynamics approach, which is effective in decision making process, also plays an important role in improving students' problem-solving skills.

The significant increase observed in experimental group 1 and 2, as a result of the experimental study, can provide evidence for considering system dynamics as an approach for defining and solving problems. Students in the experimental group 1 received higher scores than students in the experimental group 2 for they used a deductive method- they examined and modeled the problem going from whole to parts-as opposed to the students in the experimental group 2 who resorted to an inductive method.

Rote learning is fundamental problem that inhibits productivity in many aspects of life. System dynamics approach helps students focus on meaningful learning instead of rote learning as with theis approach students model a problem on their own and discover concepts, the cause and effect relationships between these concepts and the dynamic behavior of the system by experimenting. During this process, students experience making discoveries and they gain insights into the discipline of carrying out a scientific research. More effective learning takes place because students are at the center of the learning process conducting their study. 
With system dynamics approach, students will be aware of the problems around them and try to come up with alternative solutions all their lives. This approach helps them develop a scientific perspective. As a result, students will stop just passively answering the questions they are asked. They will be able to observe their environment, discover new problems and use scientific approach to model and examine these problems. Without doubt the scope of education is beyond just "teaching" certain topics to the students. Education aims to enable students define problems on their own, in addition to providing solutions to them. Defining a problem requires a deeper understanding than answering a given question (problem). It calls for making detailed observations, necessitates approaching matters with a critical point of view and being able to come up with questions that have not been asked before. People who have developed this perspective become more adaptable and productive, because they realize that truth can alter in time an under different circumstances. Such people add higher values to their environments because they unearth hidden problems and come up with effective propositions to solve these problems.

Getting accustomed to doing experiments in the micro-world prepares people for possible scenarios that may take place in the real system. When one of these scenarios start taking place, one can identify the new dynamic from the first indicators as they are already prepared for doing so.

As a result of this study, it can be said that in addition to the improvement in their problem solving skills, students using the deductive method could also determine cause and effect relationships more clearly and precisely. In order to help students better comprehend causal relationships more scenarios including such relationships can be incorporated.

\section{References}

Abbott, M. D., \& Stanley, R. S. (1999). Modeling groundwater recharge and flow in an upland fractured. bedrock aquifer. System Dynamics Review, 15(2), 163-184.

Albin, S., (1996). Four Sample Lesson Plans: Translated from German. System Dynamics in Education Project.

[Retrieved from: www.clexchange.org/ftp/documents/Implementation/IM1996FourSampleLessons.pdf]

Alessi, S. (2005). The Application of System Dynamics Modeling in Elementary and Secondary School Curricular [Retrieved from: http://web.archive.org/web/20060304015136/http://www.c5.cl/ieinvestiga/actas/ribie2 000/charlas/alessi.htm]

Andersen, J. LaVigne, A., \& Stuntz, L. (2013). Teaching Characteristics of Complex Systems in K-12 Education: Lessons Learned. The 31st International Conference of the System Dynamics Society, Cambridge, Massachusetts, USA.

Bossel, H. (2007). System Zoo 2 Simulation Models Climate, Ecosystems, Resources. Demand GmbH, Norderstedt, Germany. ISBN: 978-3-8334-8423-0

Cruz M., González M. T., Restrepo M. P., \& Zuluaga M. L. (2007). Colombian Classroom Experiments: A Preliminary Report. CLE Newsletters, 16(1),9-11.

Davidsen, P. I., Bjurklo, M., \& Wikström, H. (1993). Introducing system dynamics in schools: the Nordic experience. System Dynamics Review, 9(2), 165-181.

Deaton, M. L., \& Winebrake, J. J. (2000). Modeling of Environmental Systems. SpringerVerlag, New York.

Draper, F., \& Swanson, M. (1990). Learner-Directed Systems Education. System Dynamics Review, 7(2), 209-213. 
Evans, J. K. (1988). Application of System Dynamics as a Strategy for Teaching Management Concepts. Boston University. (Unpublished Master thesis)

Grant, W. E., Pedersen, E. K., \& Marín, S. L., (1997). Ecology and Natural Resource Management: Systems Analysis and Simulation. Wiley, New York.

Guo, H. C., L. Liu, G.H. Huang, G. A. Fuller, R. Zou, \& Y. Y. Yin. (2001). A System Dynamics Approach for Regional. Environmental Planning and Management: A study for Lake Erhai Basin. J. Environ. Manage. 61: 93-111.

Fisher, D. M. (2000). System Dynamics Models Created by High School Students. 18 th International System Dynamics Society Conference, Bergen Norway.

Fisher, D. M (2011). Everybody thinking differently: K-12 is a leverage point. System Dynamics Review, 27, (4): 394-411. DOI: 10.1002/sdr.473

Ford, A. (1999). Modeling the Environment: An Introduction to Systems Dynamics Modeling of Environmental Systems. Island Press. Washington, DC.

Forrester, J. W. (1969). Urban Dynamics. Cambridge, The MIT Press, MA, USA.

Forrester, J. W. (1971). World Dynamics. Wright-Allen Press, Cambridge, Massachusetts, MA, USA.

Forrester, J. W. (1992). Road Map 1: System Dynamics and Learner-Centered-Learning in Kindergarten through 12th Grade Education. MIT System Dynamics in Education Project.

Forrester, J. W. (1996). Road Map 1: System Dynamics and K-12 Teachers. MIT System Dynamics in Education Project.

Hassell, D. J. (1987). The role of modelling activities in the humanities curriculum, with special reference to geography: an investigate study. London: King's College.

Heppner, P. P. and Petersen, C. H. (1982). The Development and Implications of a Personal Problem-Solving Inventory. Journal of Counseling Psychology. 29(1), 66-75.

Lyneis, D. A. (2000). Bringing system dynamics to a school near you suggestions for introducing and sustaining system dynamics in K-12 education. International System Dynamics Society Conference Bergen, Norway.

Lyneis, D. A., \& Fox-Melanson, D. (2001). The Challenges of Infusing System Dynamics into a K-8 Curriculum. International System Dynamics Society Conference, Atlanta, Georgia

Mandinach, E. B., \& Cline, H. F. (1994). Classroom Dynamics: Implementing A TechnologyBased Learning Environment. Hillsdale, NJ, Lawrence Erlbaum.

MNE (Minister of National Education), (2006). New Curriculum Program.

Meadows D. H., Meadows D. L., Randers J., \& Behrens W. W. III., (1972). The Limits to Growth. New York: University Books. ISBN 0-87663-165-0

Meadows, D. H. (1973). Toward Global Equilibrium. Collected Papers, Wright-Allen Press, MA, USA.

Nail, R. F., Gelanger, S., Klinger, A., \& Peterson, E. (1992). An analysis of cost effectiveness of US energy policies to mitigate global warming, System Dynamics Review, 8, 111118.

Nuhoğlu, H. (2008). Studying Effects of Systems Approach on Attitude, Achievement, and Different Skills in Science and Technology Lesson. Unpublished PhD Dissertation, Gazi University.

Nuhoğlu, H. (2009). Evaluation of the middle school students' understanding level of basic system concepts. Elementary Education Online, 8(3): 866-882.

Penner, D. A. (2000). Explaining systems investigating middle school students' understanding of emergent phenomena. Journal of Research in Science Teaching, 37: 784-806. 
Saysel, A. K., Barlas, Y., \& Yenigun, O. (2002). Environmental sustainability in an agricultural development project: a system dynamics approach. J. Environ. Manage. 64(1): 247260.

Schecker, H. P. (1994). System Dynamics in High School Physics. International System Dynamics Conference, Stirling, Scotland.

Schecker, H. P. (2005). System Dynamics in High School Physics. [Retrieved from: didaktik.physik.uni-bremen.de/ niedderer/download/SysDyn.pdf]

Shaffer, C. S. (2006). Toward a System Dynamics Model of Teaching Computer Programming via Distance Education. Unpublished PhD Dissertation, The Pennsylvania State University.

Sterman, J. D., (2000). Business Dnamics: Systems Thinking and Modelling for a Complex World. Boston, MA: Irwin McGraw- Hill.

Ticotsky, A., Quaden, R., \& Lyneis, D. (1999). The In And Out Game: A Preliminary System Dynamics Modeling Lesson. [Retrieved from:systemdynamics.org/conferences/2001/papers/Lyneis_1.pdf]

Tinker, R. F., Nemirovsky, R., Mokros, J., \& W.T. Barclay. (1990). Measuring and modeling project-First year annual report. Cambridge, Mass. Technical Education Research Center.

Webb, M. E. (1988). An Investigation Of The Opportunities For Computer Based Modelling And The Possible Contributions To Children's Learning, in Secondary School Science. King's College, London

Vezjak, M., Savsek, T., \& Stuhler, E. A. (1998). System Dynamics Of Euthrophication Processes in Lakes. Eur. J. Oper. Res. 109 (1): 442-451.

Vizayakumar, K., \& Mohapatra, P. K. J. (1991). Environmental impact analysis of a coalfield, J. Environ. Manage. 34 (1): 73-93.

Wood, T. S., and Shelley, M. L. (1999). A dynamic model of bioavailability of metals in constructed wetland sediments. Ecol. Eng., 12(1): 231-252.

Zaraza R. J. (1995). The CC- STADUS Project: Developing and Nurturing a Cadre of PreCollegeTeachers Using System Dynamics/Computer Modeling in the Classroom. CLE Newsletters, 4(3).

Zaraza, R., and Fisher, D. (1997). Introducing System Dynamics into the traditional secondary curriculum: The CC-STADUS project's search for leverage points. The 15th International System Dynamics Conference, Istanbul, Turkey.

Zuman, J. P. and Weaver, S. L. (1988). Tools for teaching problem solving: An evaluation of a modeling and systems thinking approach. Annual NARST Conference, Lake Ozark, MO. 